\title{
Wedelolactone suppresses LPS-induced caspase-11 expression by directly inhibiting the IKK Complex
}

\author{
M Kobori ${ }^{1,2, \star}$, Z Yang ${ }^{1}$, D Gong ${ }^{3}$, V Heissmeyer ${ }^{4}$, H Zhu', \\ Y-K Jung ${ }^{1}$, M Angelica M Gakidis ${ }^{1}$, A Rao ${ }^{4}$, T Sekine ${ }^{5}$, \\ F Ikegami ${ }^{5}$, C Yuan ${ }^{3}$, and J Yuan ${ }^{\star, 1}$ \\ ${ }^{1}$ Department of Cell Biology, Harvard Medical School, Boston, MA, USA; \\ 2 National Food Research Institute, Tsukuba, Ibaraki, Japan; \\ ${ }^{3}$ Shanghai Institute of Organic Chemistry, Chinese Academy of Sciences, 354 \\ Fenglin Lu, Shanghai, China; \\ ${ }^{4}$ Center for Blood Research, 200 Longwood Avenue, Room 142, Boston, MA, \\ USA; \\ ${ }^{5}$ Graduate School of Pharmaceutical Sciences, Chiba University, Yayoi-cho \\ 1-33, Inage-ku, Chiba, Japan \\ * Corresponding authors: J Yuan, Tel: + 617-432-4170; Fax: + 617-432-4177; \\ E-mail: jyuan@hms.harvard.edu. \\ M Kobori, Tel: 81-298-38-8055; Fax: 81-298-38-7996. \\ E-mail: kobori@nfri.affrc.go.jp
}

Received 23.5.03; revised 24.7.03; accepted 05.8.03; published online 03.10.03 Edited by $\mathrm{H}$ Ichijo

\begin{abstract}
Caspase-11 is a key regulator of proinflammatory cytokine IL$1 \beta$ maturation and pathological apoptosis. Caspase-11 is not expressed in most tissues under normal condition, but highly inducible upon pathological stimulation such as in the presence of lipopolysaccharide (LPS). Here, we describe the identification and characterization of wedelolactone, a natural compound that inhibits LPS-induced caspase-11 expression in cultured cells by inhibiting NF- $\kappa$ B-mediated transcription. We demonstrate that wedelolactone is an inhibitor of IKK, a kinase critical for activation of NF- $\kappa \mathrm{B}$ by mediating phosphorylation and degradation of $I \kappa \mathrm{B} \alpha$.

Cell Death and Differentiation (2004) 11, 123-130. doi:10.1038/ sj.cdd. 4401325

Published online 3 October 2003
\end{abstract}

Keywords: wedelolactone; caspase-11; LPS; NF- $\kappa$ B; IKK

Abbreviations: LPS, lipopolysaccharide; $P \mathrm{PA}_{1}$, prostaglandin $\mathrm{A}_{1} ; \mathrm{TNF} \alpha$, tumor necrosis factor- $\alpha$

\section{Introduction}

Caspase-11, a member in the caspase-1 subfamily of cysteine proteases, is a crucial mediator of inflammatory responses and pathological cell death. ${ }^{1-3}$ Caspase- 11 activates caspase-1, which processes pro-IL-1 $\beta$ and pro-IL-18 into mature IL-1 $\beta$ and IL-18, respectively. ${ }^{1-5}$ Caspase- 11 is essential for the activation of caspase-1, as both caspase11-/- mice and caspase-11-/- embryonic fibroblast (MEF) cells are deficient in caspase- 1 activation. ${ }^{2}$ Caspase-11-/mice are defective in producing mature $\mathrm{IL}-1 \beta$ and resistant to lipopolysaccharide (LPS)-induced lethal endotoxin shock. ${ }^{2}$
Caspase-11 also plays a role in regulating apoptosis by directly activating caspase-3 under certain pathological conditions., 3,7 LPS-induced caspase-11 regulates lymphocyte apoptosis by activating capase- 3 and caspase- $7 .{ }^{6}$ The transcription of caspase-11 is highly sensitive to bacterial LPS, which has no effect on the expression level of caspase$1 .^{1,2,8}$ Therefore, the induction of caspase-11 is an important upstream controlling event in inflammatory response and apoptosis under pathological conditions. Understanding the molecular mechanism of caspase-11 induction may allow us to develop effective inhibitors of inflammatory responses. In this paper, we describe the identification and characterization of wedelolactone, a natural compound that inhibits the LPSinduced caspase-11 expression in cultured cells through inhibiting upstream NF- $\kappa$ B-mediated transcription and demonstrate that wedelolactone is an inhibitor of IKK, a kinase critical for activation of NF- $\kappa \mathrm{B}$.

\section{Result}

Eclipta prostrata L. is a herb medicine that has been used in the treatment of infective hepatitis in India, ${ }^{9}$ snake venom poisoning in Brazil, ${ }^{10}$ as well as septic shock in folk medicine in China. Since caspase-11 expression is highly sensitive to a variety of pathological stimuli and likely to be induced under these different pathological conditions, we tested the possibility that $E$. prostrata L. may contain an activity that can inhibit caspase-11 induction. We developed a culture system in which mouse BALB/c 3T3 cells were treated with bacterial LPS to induce the expression of caspase-11. The BALB/c 3T3 cells express undetectable amount of caspase-11 under the control condition (Figure 1a). The caspase-11 expression was clearly induced after the treatment of $2 \mu \mathrm{g} / \mathrm{ml} \mathrm{LPS} \mathrm{for} 6$ or $8 \mathrm{~h}$ in BALB/c 3T3 cells (Figure 1a,b). E. prostrata L. extract was prepared and examined using the BALB/C 3T3 cell system for the presence of a possible inhibitor of caspase-11 induction. Dried entire plant of $E$. prostrata L. was first extracted in ethanol. The concentrated ethanol extract was then washed with hot water and partitioned with ethyl acetate. The ethyl acetate soluble fraction was concentrated by evaporation and dissolved in a small amount of ethanol after removal of the ethyl acetate. The cells were incubated with $2 \mu \mathrm{g} / \mathrm{ml}$ LPS in the presence or absence of ethyl acetate fraction for $8 \mathrm{~h}$. Coincubation of the ethyl acetate fraction with LPS completely inhibited the caspase-11 expression induced by LPS at a concentration of $45 \mu \mathrm{l} / \mathrm{ml}$ (Figure 1a).

We tested to see if pretreatment of the ethyl acetate fraction inhibits the expression of caspase-11 after LPS treatment. Pretreatment of cells with $40 \mu \mathrm{l} / \mathrm{ml}$ of the ethyl acetate fraction for $6 \mathrm{~h}$ completely abolished the ability of cells to induce caspase-11 even after prolonged incubation of LPS for $6 \mathrm{~h}$ (Figure 1b). To test if the ethyl acetate fraction inhibits the caspase-11 expression after LPS induction, we incubated the cells with LPS for $6 \mathrm{~h}$ to induce the expression of caspase-11, 
a

$$
\begin{aligned}
& \text { LPS } \quad-+-+-+-+ \\
& \text { Eclipta p. }(\mu \mathrm{l} / \mathrm{ml})-\begin{array}{llllll}
15 & 15 & 30 & 30 & 4545
\end{array} \\
& \begin{array}{llllllll}
1 & 2 & 3 & 4 & 5 & 6 & 7 & 8
\end{array} \\
& \text { Caspase-11 } \\
& \text { - }
\end{aligned}
$$

b

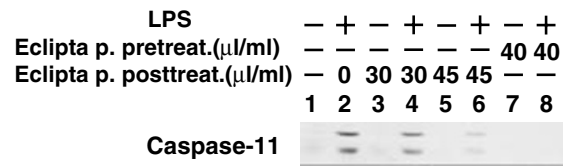

C<smiles>COc1cc(O)c2c(c1)oc(=O)c1c3cc(O)c(O)cc3oc21</smiles>

$\mathrm{m} / \mathbf{z} 315[\mathrm{M}+\mathrm{H}]^{+1}$ d

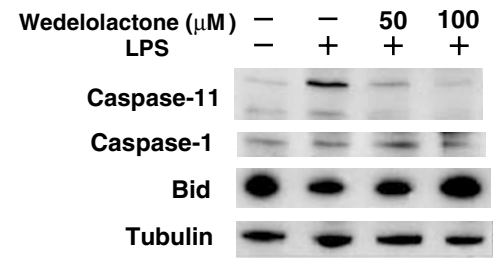

e

$\begin{array}{cccccc}\text { LPS } & - & + & + & + & + \\ \text { Wedelolactone }(\mu \mathrm{M}) & - & - & 40 & 60 & 100 \\ & 1 & 2 & 3 & 4 & 5\end{array}$

$\mathbf{f}$

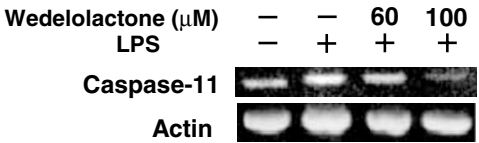

Figure 1 Wedelolactone isolated from E. prostrata L. inhibits the expression of caspase- 11 . (a) BALB/c $3 T 3$ cells $\left(2 \times 10^{5}\right.$ cells $\left./ \mathrm{ml}\right)$ were treated with LPS $(2 \mu \mathrm{g} / \mathrm{ml})$ and indicated amounts of the ethylacetate fraction of $E$. prostrata $\mathrm{L}$. for $8 \mathrm{~h}$. The protein levels of caspase-11 in the cells were examined by Western blot analysis using anticaspase-11 antibody. (b) BALB/c 3T3 cells were treated with ethylacetate fraction of Eclipta prostrata L. for $6 \mathrm{~h}$ before (E. prostrata pretreat.) or after (E. prostrata post-treat.) $2 \mu \mathrm{g} / \mathrm{ml}$ LPS treatment for $6 \mathrm{~h}$. The protein levels of caspase-11 in the cells were examined by Western blot analysis. (c) The structure of wedelolactone. (d) $\mathrm{BALB} / \mathrm{c} 3 \mathrm{~T} 3 \mathrm{cells}$ were treated with purified wedelolactone for $1 \mathrm{~h}$ and treated with LPS $(2 \mu \mathrm{g} / \mathrm{ml})$ for additional $6 \mathrm{~h}$. The protein levels of caspase-11, caspase-1, Bid and tubulin in the cells were examined by Western blots. (e) BALB/c $3 T 3$ cells were treated with LPS $(2 \mu \mathrm{g} / \mathrm{ml})$ for 30 min and then treated with wedelolactone for $5.5 \mathrm{~h}$. The protein levels of caspase-11 in the cells were examined by Western blot analysis. (f) BALB/c $3 T 3$ cells were incubated with wedelolactone for $1 \mathrm{~h}$ and then treated with LPS $(2 \mu \mathrm{g} / \mathrm{ml})$ for $6 \mathrm{~h}$. RT-PCR was performed using primers to caspase-11, and actin was used as a control. PCR-amplified products were separated by electrophoresis and visualized by ethidium bromide stain

and then exchanged into the ethyl acetate fraction-containing medium for an additional $6 \mathrm{~h}$. Treatment of 30 and $45 \mu \mathrm{l} / \mathrm{ml}$ of the ethyl acetate fraction but not solvent inhibited LPSinduced caspase-11 expression in the cells (Figure 1b). Thus, the extract was effective in inhibiting caspase-11 in cells both before and after LPS treatment.

We purified the active component in the ethyl acetate fraction by Toyopearl HW40 column chromatography followed by reverse-phase HPLC (ODS) using the induction of caspase-11 in Balb/c 3T3 cells as the assay system. The active component in the ethyl acetate fraction precipitated in ethanol with the elapse of time, which gave us a relatively high yield. The precipitate was redissolved in a small amount of DMSO and then recrystallized from ethanol. The isolated component was $99.7 \%$ pure by reverse-phase HPLC(ODS) analysis. The UV spectrum of the isolated active component was identical to that of wedelolactone reported to be present in E. prostrata L. ${ }^{9}$ The ESI-MS spectra showed the pseudo-molecular ion $[\mathrm{M}+\mathrm{H}]+$ peak at $\mathrm{m} / \mathrm{z} 315$. ${ }^{1} \mathrm{H}$ and ${ }^{13} \mathrm{C}$ NMR including 2D NMR (COSY, HSQC and $\mathrm{HMBC}$ ) spectra data suggested the structure of active component as wedelolactone (Figure 1c). The MS and NMR spectra data of purified active component were in agreement with the data of synthesized wedelolactone ( $Z$ Yang, M Kobori and J Yuan, unpublished data). These results led us to conclude that wedelolactone is the active component in E. prostrata L. inhibiting LPS-induced expression of caspase-11.
We determined the dose-dependence of purified wedelolactone in inhibiting caspase- 11 induction. Treatment with $50 \mu \mathrm{M}$ of wedelolactone inhibited the expression of caspase-11 to about $30 \%$ of that in LPS-treated cells. The effect of wedelolactone was specific as it inhibited the expression of caspase- 11 but not that of caspase-1 and Bid (Figure 1d). We estimated $I_{50}$ of wedelolactone in inhibition of caspase-11 induced by LPS to be about $35 \mu \mathrm{M}$. Wedelolactone also inhibited caspase-11 expression in cells prestimulated by LPS (Figure 1e). Synthetic wedelolactone inhibited the caspase-11 expression almost in the same dose-dependent manner (Figure 2b) and is used in all subsequent experiments. Wedelolactone entirely inhibited the expression of caspase-11 at a concentration of $80 \mu \mathrm{M}$ with little effect on cell viability (Figure $2 b$ ).

The induction of caspase-11 expression is mediated predominantly at the transcriptional level. ${ }^{1}$ Intraperitoneal injection of LPS in mice resulted in the increase of the caspase-11 transcript level up to 40 -fold in $4 \mathrm{~h}$. To determine if wedelolactone inhibits the transcriptional induction of caspase-11, we measured the levels of caspase-11 mRNA by RT-PCR in BALB/c 3T3 cells treated with LPS in the presence or absence of wedelolactone. LPS-induced caspase-11 mRNA expression was reduced to control levels after $1 \mathrm{~h}$ of treatment in $60 \mu \mathrm{M}$ of wedelolactone (Figure 1f). These results suggest that wedelolactone most likely inhibits the induction of caspase-11 at the level of transcription.

To determine the structural requirement for wedelolactone to inhibit the induction of caspase-11 in BALB/c cells, we 
a

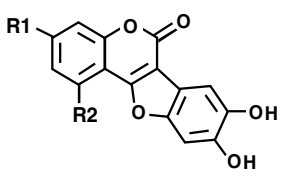

Wedelolactone : R1= $\mathrm{OCH} 3, \mathrm{R} 2=\mathrm{OH}$ Demethylwedelolactone : R1=OH, R2=OH 1,2-Dihydroxy coumestan : R1=H, R2=H (1) : $\mathrm{R} 1=\mathrm{OCH}_{3}, \mathrm{R} 2=\mathrm{H}$

(2) : R1=OH, R2=H

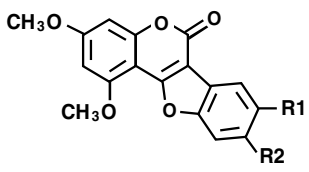

(4) : R1 $=\mathrm{OCH}_{3}, \mathrm{R} 2=\mathrm{OCH}$ (5) : R1=H, R2=H

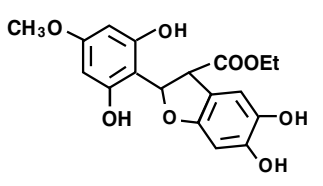

(3)

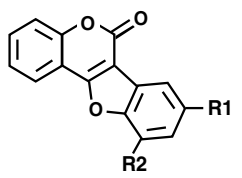

(6) : R1=CHO, R2=H

(7): $\mathrm{R} 1=\mathrm{CH} 3, \mathrm{R} 2=\mathrm{OCH} 3$
(8) : $\mathrm{R} 1=\mathrm{CO}_{2} \mathrm{CH}_{3}, \mathrm{R} 2=\mathrm{OCH}_{3}$

b

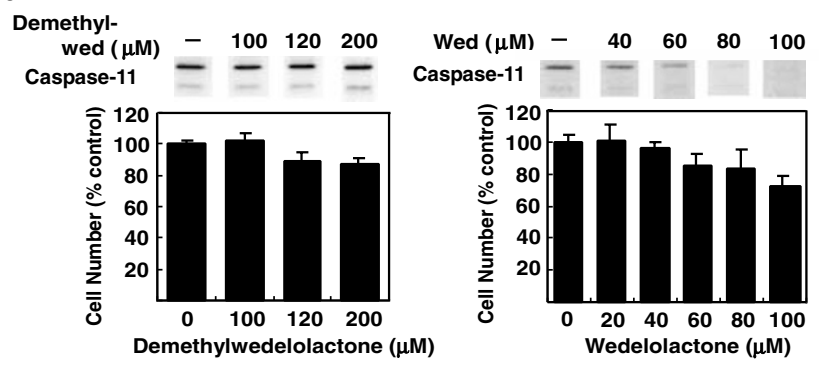

Figure 2 Wedelolactone but not its close derivatives inhibited the caspase-11 expression. (a) Structures of wedelolactone and its synthetic derivatives tested. (b) BALB/C 3 T3 cells were treated with synthetic wedelolactone and demethylwedelolactone for $1 \mathrm{~h}$ and then treated with LPS $(2 \mu \mathrm{g} / \mathrm{ml})$ for $6 \mathrm{~h}$. The protein levels of caspase- 11 in the cells were examined by Western blots (top). Viable cell numbers were determined by hemocytometer and each value is the mean \pm S.D. of triplicate cultures (bottom)

tested several derivatives of wedelolactone. We synthesized demethylwedelolactone, 11,12-dihydroxy coumastan or 46 other wedelolactone derivatives including 1-8 in Figure 2a, and compared the inhibitory effect on the LPS-induced caspase-11 expression with wedelolactone. Only wedelolactone but not demethylwedelolactone and other derivatives inhibited the expression of caspase-11 in BALB/c 3T3 cells (Figure 2b, data not shown). Our results suggest that there is a very stringent structural requirement for inhibiting the induction of caspase-11 by wedelolactone.

We also tested if wedelolactone may inhibit the release of $\mathrm{IL}-1 \beta$ from primary splenocytes. The treatment of mouse splenocytes from C57/B6 mice by LPS induced the maturation and release of $\mathrm{IL}-1 \beta$. The addition of 50 and $100 \mu \mathrm{M}$ wedelolactone inhibited the $\mathrm{IL}-1 \beta$ secretion in a dosedependent manner (Figure 3).

The transcriptional factor $\mathrm{NF}-\kappa \mathrm{B}$ plays a critical role in controlling the expression of genes involved in inflammation, immune response and apoptosis. ${ }^{11}$ Caspase-11 induction is regulated by $\mathrm{NF}-\kappa \mathrm{B} .{ }^{12,13}$ Since wedelolactone inhibits the transcriptional increase of caspase-11 induced by LPS, we examined the effect of wedelolactone on the LPS-induced NF$\kappa \mathrm{B}$ transcriptional activation in BALB/c cells. The cells transfected with $\mathrm{NF}-\kappa \mathrm{B}$ or p53 luciferase reporter plasmids were treated with wedelolactone for $1 \mathrm{~h}$, stimulated with LPS for $9 \mathrm{~h}$ and then measured for NF- $\kappa \mathrm{B}$ or p53 transcriptional activity by the luciferase assay. Wedelolactone inhibited the $\mathrm{NF}-\kappa \mathrm{B}$ transcriptional activity at the similar dose range as that of caspase-11 expression, but had no effect on the p53 reporter activity (Figure $4 \mathrm{a}$ ). The treatment of 11,12-dihydroxycoumestan that had no effect on the caspase-11 expression also did not inhibit the NF- $\kappa$ B reporter activity (Figure $4 b)$. We also determined the effect of wedelolactone on the LPSinduced NF- $\kappa$ B p65 DNA binding activity in BALBc cells. The cells were treated with wedelolactone for $1 \mathrm{~h}$ and stimulated with LPS for 30 or $60 \mathrm{~min}$. The NF- $\kappa$ B promoter binding activity was determined by its affinity to the immobilized oligonucletide containing an NF- $\kappa \mathrm{B}$ consensus binding site. The NF- $\kappa \mathrm{B}$ p65 bound to the oligonucleotide was detected by enzyme-linkedimmuno-assay (ELISA). Wedelolactone (40 and $80 \mu \mathrm{M})$ significantly inhibited NF- $\kappa$ B p65 DNA binding activity induced by LPS in BALBc cells (Figure 5 ). Taking all the results together, we propose that wedelolactone inhibits the induction of caspase-11 through inhibiting NF- $\kappa$ B activation.

The activity of NF- $\kappa \mathrm{B}$ is normally sequestered in the cytoplasm and nuclear translocation is an important step in its activation. ${ }^{14}$ The subcellular location of NF- $\kappa \mathrm{B}$ is controlled by a family of inhibitory proteins, $I_{\kappa} \mathrm{Bs}$, such as $I_{\kappa} \mathrm{B} \alpha$, which bind $\mathrm{NF}-\kappa \mathrm{B}$ to maintain the cytoplasmic localization of $\mathrm{NF}-\kappa \mathrm{B}$ in unstimulated cells. ${ }^{14}$ Exposure of cells to a variety of extracellular stimuli leads to the rapid phosphorylation, ubiquitination, and ultimately proteolytic degradation of $I_{\kappa} \mathrm{B} \alpha$, which allows the nuclear translocation of $\mathrm{NF}-\kappa \mathrm{B}$ where it binds to DNA and regulates gene transcription. ${ }^{11,14}$

Both LPS and TNF $\alpha$ induce NF- $\kappa$ B transcriptional activity through the degradation of the inhibitor $I_{\kappa} \mathrm{B}$. These external signals act through their respective receptors to activate the $\mathrm{I} \kappa \mathrm{B}$ kinase $(\mathrm{IKK})$ complex, which contains the catalytic subunits $\mathrm{IKK} \alpha$ and $\mathrm{IKK} \beta$, and the regulatory subunit $\mid \mathrm{KK} \gamma /$ NEMO. ${ }^{11,15} \mathrm{I}_{\kappa} \mathrm{B}$ is then phosphorylated by activated IKK, polyubiquitinated and degraded by the proteasome pathway. ${ }^{12}$ We determined the possible effect of wedelolactone on the proteasome-dependent degradation of $\mathrm{I}_{\kappa} \mathrm{B} \alpha$. The phosphorylation of $\mathrm{I}_{\kappa} \mathrm{B} \alpha$ was observed after $\mathrm{TNF} \alpha$ stimulation for 5 min using anti-phospho-S32 antibody, (Figure 6a, Lane 2, bottom blot), which is an important signal for initiation of its

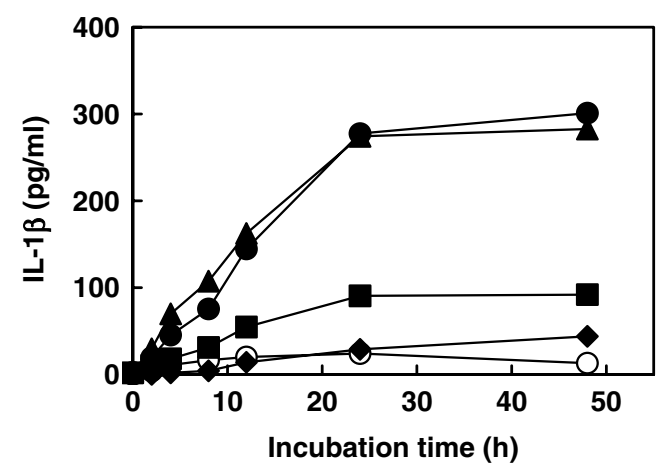

Figure 3 Wedelolactone suppressed the IL- $1 \beta$ secretion of mouse splenocytes. Primary splenocytes isolated from $\mathrm{C} 57 / \mathrm{B} 6$ mouse were preincubated with wedelolactone $(\mathbf{\Delta} 10 \mu \mathrm{M}, \mathbf{\square} 5 \mu \mathrm{M},-100 \mu \mathrm{M})$ for $1 \mathrm{~h}$ and then incubated with LPS $(1 \mu \mathrm{g} / \mathrm{ml})$. Closed circle, LPS alone and open circle, no LPS treatment. The IL- $1 \beta$ levels in the culture medium were evaluated by ELISA 
a
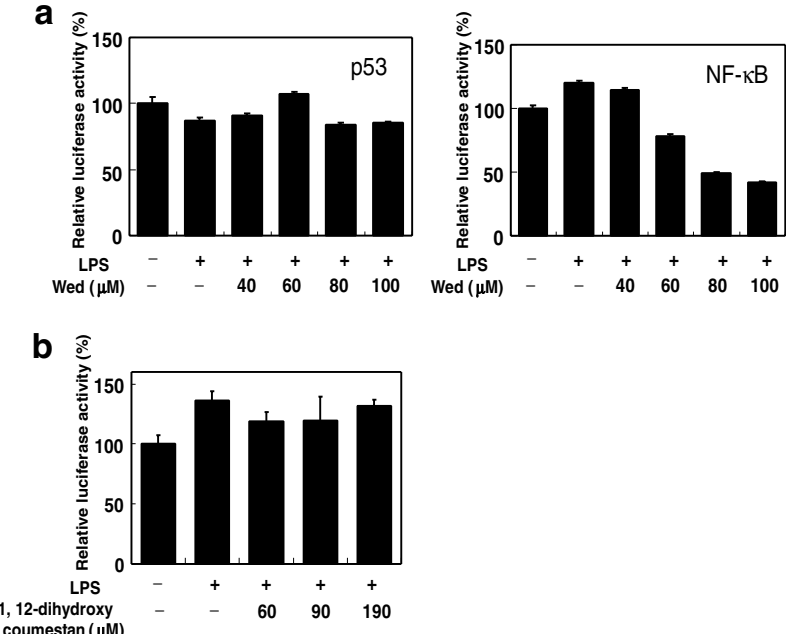

Figure 4 Wedelolactone inhibited the NF- $\kappa$ B transcriptional activity. (a) The $\mathrm{BALB} / \mathrm{c} 3 \mathrm{~T} 3$ cells were transfected with NF- $\kappa \mathrm{B}$ or $\mathrm{p} 53$ luciferase reporter plasmid. The transfected cells were treated with wedelolactone for $1 \mathrm{~h}$ and LPS $(2 \mu \mathrm{g} / \mathrm{ml})$ for $9 \mathrm{~h}$. Each value is the mean \pm S.D. of a representative experiment done in triplicate. (b) The BALB/c 3T3 cells were transfected with NF- $\kappa$ B luciferase reporter plasmid. The transfected cells were treated with 11,12-dihydroxycoumestan for $1 \mathrm{~h}$ and LPS $(2 \mu \mathrm{g} / \mathrm{ml})$ for $9 \mathrm{~h}$. Each value is the mean \pm S.D. of a representative experiment done in triplicate

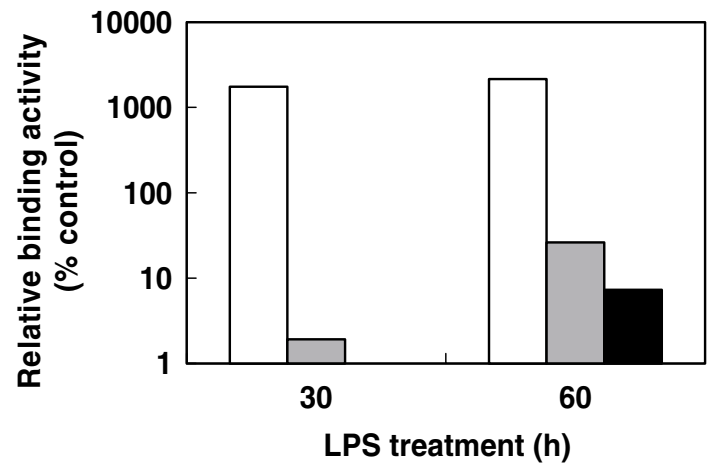

Figure 5 Wedelolactone inhibited the NF- $\kappa$ B DNA binding activity. BALB/c cells were incubated with wedelolactone $(40 \mu \mathrm{M}, 80 \mu \mathrm{M})$ for $1 \mathrm{~h}$ and LPS $(2 \mu \mathrm{g} /$ $\mathrm{ml}$ ) for 30 or $60 \mathrm{~min}$. Open box indicates LPS treatment without pretreatment with wedelolactone. The NF- $\kappa$ B p65 DNA binding activity was determined by TransAM NF- $\kappa$ B p65 Chemi kit (Active Motif)

degradation. ${ }^{11,16}$ Reduction of $\mathrm{I} \kappa \mathrm{B} \alpha$ was observed after treating with $\mathrm{TNF} \alpha$ for $10 \mathrm{~min}$ (Figure $6 \mathrm{a}$, Lane 4 , top blot). Treatment of wedelolactone inhibited the phosphorylation as well as the degradation of $\mathrm{I}_{\kappa} \mathrm{B} \alpha$ (Figure $6 \mathrm{a}$ ).

Phosphorylation of $\mathrm{I}_{\kappa} \mathrm{B} \alpha$ has been proposed as a signal for ubiquitination of $\mathrm{I}_{\kappa} \mathrm{B} \alpha^{16}$ To examine if ubiqutination of $\mathrm{I}_{\kappa} \mathrm{B} \alpha$ is inhibited by wedelolactone, the BALB/c cells were treated with or without $100 \mu \mathrm{M}$ wedelolactone for $1 \mathrm{~h}$ and stimulated with $2 \mathrm{ng} / \mathrm{ml} \mathrm{TNF} \alpha$ for 3 or $5 \mathrm{~min}$. Ubiquitinated $\mathrm{I}_{\kappa} \mathrm{B} \alpha$ was detected with an antiubiquitin antibody after immunoprecipitation with an anti- $I_{\kappa} \mathrm{B} \alpha$ antibody. The polyubiquitinated $\mid \kappa \mathrm{B} \alpha$ was induced after the stimulation of TNF $\alpha$ for $3 \mathrm{~min}$ and the pretreatment of wedelolactone resulted in an increase in $\mathrm{I}_{\kappa} \mathrm{B} \alpha$ a

$\begin{array}{cccccccc}\mathrm{TNF} \alpha(\min ) & - & 5 & 5 & 10 & 10 & 20 & 20 \\ \text { Wedelolactone } & - & \frac{1}{2} & + & - & + & - & + \\ \mathrm{I \kappa B} \alpha & 0 & & & & & & \end{array}$

Phospho-IkB $\alpha$

(Ser32)

b $\mathrm{TNF} \alpha(\min )-33$

Wedelolactone --+

[Ub]n-IkB $\alpha$

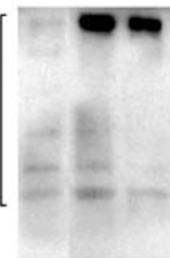

$\operatorname{I\kappa B} \alpha$
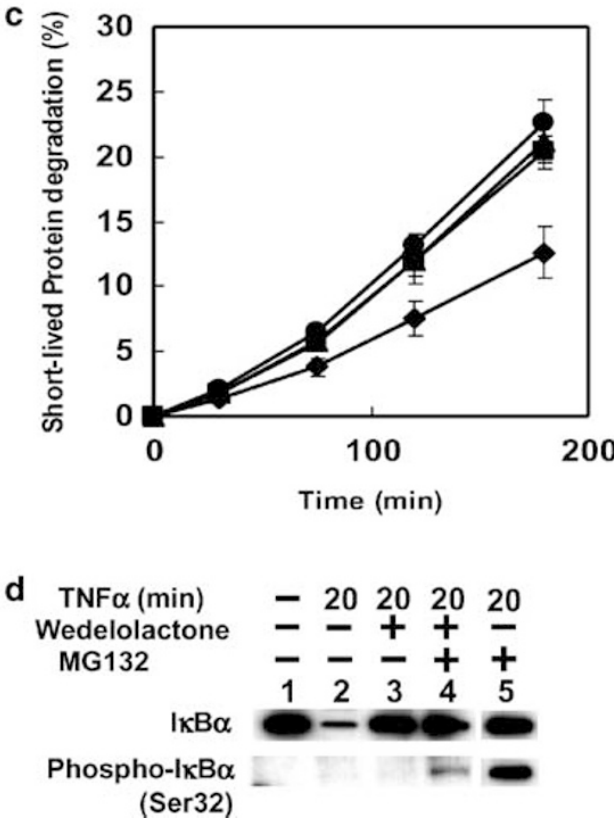

Figure 6 Wedelolactone inhibited the phosphorylation and degradation of $\left.\right|_{\kappa} \mathrm{B} \alpha$ but not proteasome activity in general. (a) BALB/c $3 T 3$ cells were incubated with wedelolactone $(100 \mu \mathrm{M})$ for $1 \mathrm{~h}$ and TNF $\alpha(2 \mathrm{ng} / \mathrm{ml})$ for 5,10 or $20 \mathrm{~min}$. The protein levels of $\left.\right|_{\kappa} \mathrm{B} \alpha$ and phospho (Ser32)- $\mid \kappa \mathrm{B} \alpha$ in the cells were examined by Western blots using antiphospho-I $\kappa \mathrm{B} \alpha$ (Ser32)-specific antibody. (b) BALB/c 3T3 cells were preincubated with wedelolactone $(100 \mu \mathrm{M})$ for $1 \mathrm{~h}$ and TNF $\alpha(2 \mathrm{ng} / \mathrm{ml})$ for $3 \mathrm{~min}$. Cells were harvested and a part of the cytosolic extract was subjected to Western blots with anti-I $\kappa \mathrm{B} \alpha$. The rest of the extracts were immunoprecipitated with anti- $I_{\kappa} \mathrm{B} \alpha$ antibody. The immunoprecipitates were then analyzed by Western blots with antiubiquitin antibody. (c) BALB/c 3T3 cells were incubated with $5 \mu \mathrm{Ci}$ $\mathrm{ml}\left[{ }^{3} \mathrm{H}\right]$ tyrosine for $1 \mathrm{~h}$ and then incubated with an excess amount of tyrosine in the absence $(\mathbf{O})$ or presence of wedelolactone $(\Delta 100 \mu \mathrm{M}, \mathbf{\square} 200 \mu \mathrm{M})$ or MG132 $\diamond 20 \mu \mathrm{M})$. The short-lived proteins degradation was determined as the ratio of tritium in the medium to total amount of incorporated tritium. Each value is the mean + S.D. of a representable experiment done in triplicate. (d) BALB/C 3T3 cells were preincubated with wedelolactone $(100 \mu \mathrm{M})$ and/or together with MG132 $(20 \mu \mathrm{M})$ for $1 \mathrm{~h}$, and then incubated with TNF $\alpha(2 \mathrm{ng} / \mathrm{ml})$ for $20 \mathrm{~min}$. Cells were harvested and the extracts were immunoprecipitated with anti- $\kappa_{\kappa} \mathrm{B} \alpha$ antibody. The immunoprecipitates were then analyzed by Western blot analysis using anti-phospho- $\mathrm{I}_{\kappa} \mathrm{B} \alpha$ (Ser32)-specific antibody 
levels and a simultaneous reduction in the levels of ubiquitination (Figure 6b). These results indicated that wedelolactone acts predominantly through inhibition of phosphorylation that precedes ubiquitination and degradation of $\mathrm{I} \kappa \mathrm{B} \alpha$. We ruled out a possible effect of wedelolactone on proteasome by measuring the degradation of short-lived proteins. Wedelolactone has no effect on the degradation of short-lived proteins in the concentration effective for inhibiting caspase-11 expression and NF- $\kappa \mathrm{B}$ activation (Figure $6 \mathrm{c}$ ). MG132 inhibited protein degradation and induced the accumulation of phosphorylated $I_{\kappa} \mathrm{B} \alpha$ in the cells stimulated by $2 \mathrm{ng} / \mathrm{ml} \mathrm{TNF} \alpha$, whereas any phosphorylated $\mathrm{I}_{\kappa} \mathrm{B} \alpha$ was not detected in the cells that were pretreated with $100 \mu \mathrm{M}$ wedelolactone for $1 \mathrm{~h}$ and stimulated by $2 \mathrm{ng} / \mathrm{ml}$ TNF $\alpha$ for 20 min (Figure 6d).

To characterize further the mechanism of wedelolactone, we examined the effect of wedelolactone on IKK activity, which catalyzed the phosphorylation of $\mathrm{I}_{\kappa} \mathrm{B} \alpha$. We found that wedelolactone inhibited TNF $\alpha$ endogenous IKK activity in vitro (Figure 7a). The $\mathrm{IC}_{50}$ for inhibition of IKK activity immunoprecipitated from lysates of $5 \times 10^{6}$ cells was between 10 and $20 \mu \mathrm{M}$ (Figure 7a). Pretreatment of $20 \mu \mathrm{M}$ wedelolactone also completely inhibited the IKK activity in vitro (Figure 7b). Thus,
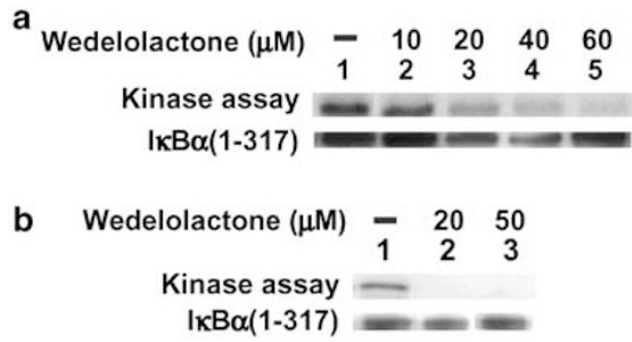

C

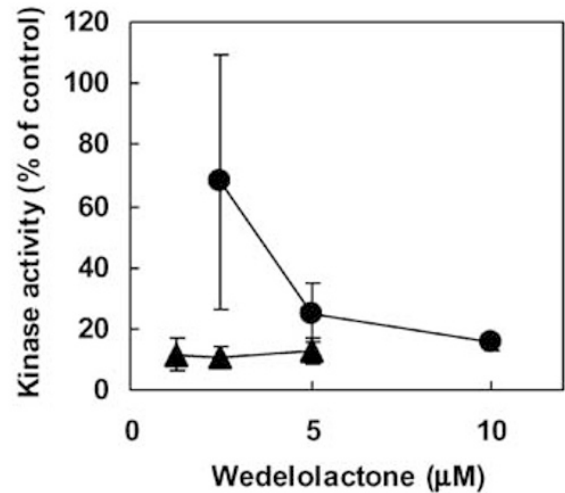

Figure 7 Wedelolactone inhibited IKK activity in vitro. (a) BALB/c 3T3 cells treated with TNF $\alpha(20 \mathrm{ng} / \mathrm{ml})$ for $15 \mathrm{~min}$. IKK was immunoprecipitated from the lyastes of TNF $\alpha$-treated cells $\left(5 \times 10^{6}\right.$ cells) and incubated with recombinant $\mathrm{I}_{\kappa} \mathrm{B} \alpha(1-317),\left[\gamma^{32}{ }^{32} \mathrm{P}\right] \mathrm{ATP}$ and indicated amounts of wedelolactone at $30^{\circ} \mathrm{C}$ for $30 \mathrm{~min}$. Kinase activity was quantified by phosphoimaging. The protein level of $\mathrm{I}_{\kappa} \mathrm{B} \alpha(1-317)$ in the assay was detected by Western blot analysis. (b) Immunoprecipitated IKK was pretreated with wedelolactone at $30^{\circ} \mathrm{C}$ for $30 \mathrm{~min}$ washed four times with kinase buffer and assayed for the kinase activity. (c) IKK was immunoprecipitated from the TNF $\alpha$-treated BALB/c 3 T3 cells $\left(1.7 \times 10^{6}\right.$ cells). Wedelolactone was added into a kinase assay $(-)$ or immunoprecipitated IKK was pretreated with wedelolactone at $30^{\circ} \mathrm{C}$ for $30 \mathrm{~min}$ before the assay $(\mathbf{A})$. Kinase activity was quantified by phosphoimaging. Each value is the mean \pm S.D. of a representative experiment done in triplicate it is possible that wedelolactone inhibits IKK activity irreversibly. The inhibitory effect of the wedelolactone pretreatment on the IKK activity was compared with that of the direct addition of wedelolactone in the kinase assay (Figure 7c). The pretreatment of wedelolactone was more effective in inhibiting IKK activity (Figure 7c).

Wedelolactone also inhibited the kinase activities of transfected IKK $\beta$ and IKK $\alpha$ (Figure 8a and b). Wedelolactone inhibited the endogenous IKK activity of human HeLa cells as well as the mouse BALB/c 3T3 cells in vitro (Figure 9a). The effect of wedelolactone on IKK is specific, as it has no effect on the activities of p38 MAP kinase or Akt (data not shown).

Cyclopentenone prostaglandins (cyPGs) such as $\mathrm{PGA}_{1}$ were suggested to inhibit IKK activity through the direct inhibition of $\mathrm{IKK} \alpha$ and IKK $\beta{ }^{17}$ We compared the inhibitory effect of wedelolactone with that of $P G A_{1}$ on the IKK activity in the $B A L B / c$ 3T3 cells. In the presence of equivalent concentration of wedelolactone and $\mathrm{PGA}_{1}$, wedelolactone worked much more effectively in inhibiting IKK activity (Figure 9b). Consistent with the in vitro IKK assay, $\mathrm{PGA}_{1}$ also worked less efficiently in inhibiting caspase-11 induction at $100 \mu \mathrm{M}$ than that of wedelolactone (Figure 9c). We conclude that wedelolactone is a more effective inhibitor of IKK than that of $P G A_{1}$.

To test if wedelolactone and $\mathrm{PGA}_{1}$ may have additive or synergistic inhibitory activity on IKK, we treated BalB/c 3T3 cells with suboptimal doses of either wedelolactone or $\mathrm{PGA}_{1}$ individually or in combination (Figure 9d). The presence of

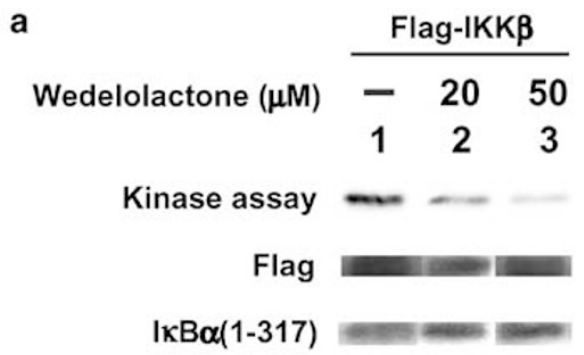

b

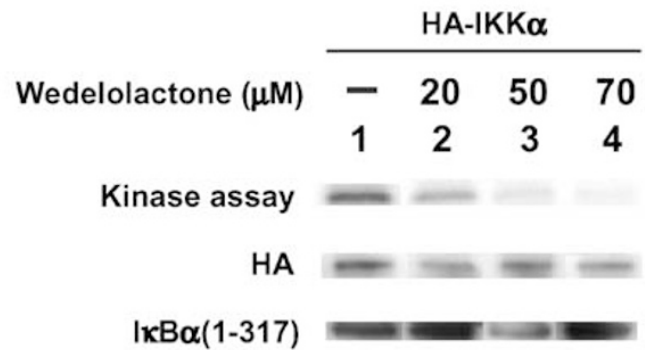

Figure 8 Wedelolactone inhibited kinase activities of transfected $\operatorname{IKK} \beta$ and IKK $\alpha$ in vitro. The BALB/c 3T3 cells transfected with Flag-tagged IKK $\beta$ (a) or HAtagged IKK $\alpha(\mathbf{b})$ were treated with TNF $\alpha(20 \mathrm{ng} / \mathrm{ml})$ for $15 \mathrm{~min}$. IKK $\beta$ or IKK $\alpha$ was immunoprecipitated from the lysates of TNF $\alpha$-treated cells $\left(5 \times 10^{6}\right.$ cells) and incubated with $\mid \kappa \mathrm{B} \alpha(1-317),\left[\gamma^{32} \mathrm{P}\right.$ ]ATP and indicated amounts of wedelolactone at $30^{\circ} \mathrm{C}$ for $30 \mathrm{~min}$. Kinase activity was quantified by phosphoimaging. The protein levels of Flag, $\mathrm{HA}$ and $\mathrm{I} \kappa \mathrm{B} \alpha(1-317)$ in the assay was detected by Western blots 


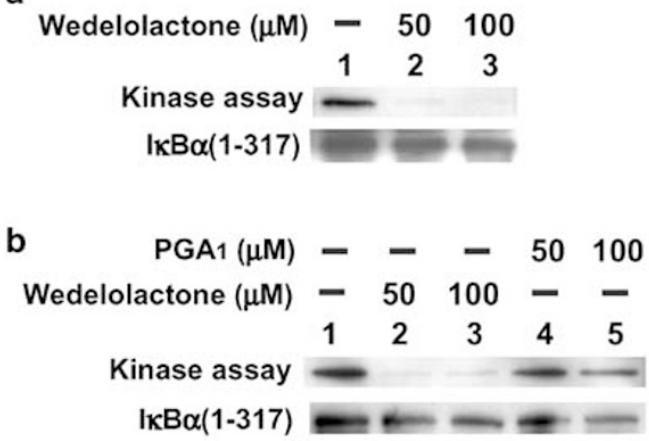

C

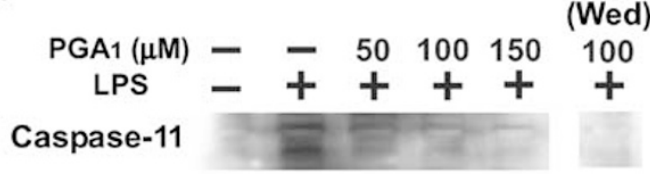

d

\begin{tabular}{|c|c|c|c|c|}
\hline \multirow{3}{*}{$\begin{array}{r}\text { PGA1 }(\mu \mathrm{M}) \\
\text { Wedelolactone }(\mu \mathrm{M})\end{array}$} & 一 & 一 & 100 & 100 \\
\hline & - & 20 & - & 20 \\
\hline & 1 & 2 & 3 & 4 \\
\hline Kinase assay & - & $=$ & - & - \\
\hline$(\%)$ & 100 & 27 & 78 & 45 \\
\hline
\end{tabular}

Figure 9 Comparison of inhibitory activities of wedelolactone and $P G A_{1}$. (a) HeLa cells were treated with TNF $\alpha(20 \mathrm{ng} / \mathrm{ml})$ for $15 \mathrm{~min}$. The immunoprecipitated IKK from the TNF $\alpha$-treated cells $\left(5 \times 10^{6}\right.$ cells) was incubated with substrate $I_{\kappa} \mathrm{B} \alpha(1-317)$, ATP- $\gamma-\mathrm{S}$ and indicated amounts of wedelolactone at $30^{\circ} \mathrm{C}$ for $30 \mathrm{~min}$. Thiophospho- $I_{\kappa} \mathrm{B} \alpha$ and $I_{\kappa} \mathrm{B} \alpha(1-317)$ were detected by Western blot analysis using antithiophosphate. (b) BALB/c $3 T 3$ cells were treated with TNF $\alpha(20 \mathrm{ng} / \mathrm{ml})$ for $15 \mathrm{~min}$. The immunoprecipitated IKK was incubated with $I_{\kappa} \mathrm{B} \alpha(1-317)$, ATP- $\gamma-\mathrm{S}$ and indicated amounts of wedelolactone or $\mathrm{PGA}_{1}$ at $30^{\circ} \mathrm{C}$ for $30 \mathrm{~min}$. Thiophospho- $\left.\right|_{\kappa} \mathrm{B} \alpha$ and $\mathrm{I}_{\kappa} \mathrm{B} \alpha(1-317)$ were detected by Western blots. (c) The immunoprecipitated IKK was incubated with $I_{\kappa} B \alpha(1-317),\left[\gamma{ }^{32} \mathrm{P}\right.$ JATP, and wedelolactone, $P G A_{1}$ or wedelolactone and $P G A_{1}$ together at $30^{\circ} \mathrm{C}$ for $30 \mathrm{~min}$. Kinase activity was quantified by phosphoimaging. The protein levels of $\mid \kappa B \alpha(1-317)$ in the assay were detected by Western blot analysis. (d) BALB/C $3 T 3$ cells were treated with $P_{G A}$ or wedelolactone for $1 \mathrm{~h}$ and then treated with LPS $(2 \mu \mathrm{g} / \mathrm{ml})$ for $6 \mathrm{~h}$. The protein levels of caspase- 11 in the cells were examined by Western blot analysis

$P G A_{1}$ definitively did not promote the activity of wedelolactone in inhibition of IKK activity (Figure 9d), consistent with the proposal that both $\mathrm{PGA}_{1}$ and wedelolactone inhibit IKK directly.

Taken together, we conclude that wedelactone most likely inhibits the induction of caspase-11 through direct inhibition of $\mathrm{IKK}$ activity and subsequent $\mathrm{I}_{\kappa} \mathrm{B} \alpha$ phosphorylation.

\section{Discussion}

Wedelolactone has been identified as a coumestan contained in E. prostrata L. and was suggested to be the active component of this herb in fighting against hepatitis and snake venoms. ${ }^{9,10}$ Here, we demonstrated that wedelolactone has anti-inflammatory effect through inhibiting IKK activity and caspase-11 expression. Wedelolactone inhibited the secretion of the proinflammatory cytokine $\mathrm{IL}-1 \beta$, which maturated by caspase-11-activated caspase-1, from mouse splenocytes. The other major components of $E$. prostrata $L$. are flavonoids luteolin and apigenin that did not show inhibitory effect on caspase-11 induction when tested (M Kobori and $\mathrm{J}$ Yuan, data not shown). Interestingly, demethylwedelolactone, in which a methoxy group of wedelolactone is substituted by a hydroxyl group, also found in E. prostrata L. and other 46 synthestic wedelolactone derivatives had no inhibitory activity towards caspase-11 expression. The structural requirement for wedelolactone to inhibit IKK and caspase-11 induction is very stringent.

The NF- $\kappa \mathrm{B}$ activity is mainly regulated by the levels of $I_{\kappa}$ B's. ${ }^{11}$ One of the well-known $I_{\kappa} \mathrm{Bs}$ is $I_{\kappa} \mathrm{B} \alpha$, which forms $\mathrm{NF}-\kappa \mathrm{B}-\mathrm{I}_{\kappa} \mathrm{B}$ complex with p65/p50 NF- $\kappa \mathrm{B}$ heterodimer. $I_{\kappa} \mathrm{B} \alpha$ is phosphorylated at $\mathrm{S} 32$ and $\mathrm{S} 36$ by IKK complex, and then degraded through the ubiquitin-proteasome pathway. ${ }^{16,18} \mathrm{IKK} \beta$ activation was shown to be essential for the IKK and the following NF- $\kappa \mathrm{B}$ activation by LPS and other proinflammatory stimuli. ${ }^{19-21}$ More recently, caspase11 expression was reported to be dependent on $\mathrm{IKK} \alpha$ and NEMO in MEF cells. ${ }^{12}$ Wedelolactone inhibits the phosphorylation of $I_{\kappa} \mathrm{B} \alpha$. Some of the natural compounds were shown to inhibit NF- $\kappa \mathrm{B}$ activity through the inhibition of IKK. PGA 1 and the anti-inflammatory natural product parthenolide were reported to inhibit IKK $\beta$ activity directly. ${ }^{17,22}$ They are suggested to inhibit $\mathrm{IKK} \beta$ activity through the direct modification. IKK $\alpha$ and IKK $\beta$ contain cysteine 179 within their active loop. ${ }^{17}$ Mutation at cysteine 179 of IKK $\beta$ rendered a constitutively active $I \mathrm{KK} \beta$ resistant to $P G A_{1}, 15 \mathrm{dPGJ}_{2}$ and parthenolid. ${ }^{17,22}$ Vitamin $C$ inhibited the IKK activity via the activation of $\mathrm{p} 38 .{ }^{23}$ Wedelolactone directly inhibited the IKK activity in vitro, whereas had no effect on phosphorylation of p38 and Akt (data not shown). Increasing concentration of ATP in a kinase assay using ATP- $\gamma-S$ as a phosphorylation level did not affect the inhibition of IKK activity by wedelolactone (data not shown). Thus, wedelolactone was not likely to be a competitive inhibitor of ATP binding. Wedelolactone most likely inhibits the phosphorylation of $I_{\kappa} \mathrm{B} \alpha$ by directly inhibiting IKK activity in an irreversible fashion. It is obvious of great interest to determine the effect of wedelolactone in animals. The limited availability of synthetic wedelolactone, however, has so far hindered our experimental progress in this regard. The ability of wedelolactone to inhibit the activation of NF- $\kappa \mathrm{B}$ pathway provides an interesting prospective for using this compound as a potential lead compound in anti-inflammatory therapy to inhibit IL-1 $\beta$ levels in diseases such as rheumatoid arthritis, asthma and septic shock.

\section{Materials and Methods}

\section{Cells and cell culture}

BALB/c 3T3, and mouse splenocytes were grown in Dulbecco's modified Eagle's medium (DMEM, Invitrogen) supplemented with 10\% FCS (Bioserum). HeLa cells (RCB007, RIKEN Cell Bank, Tsukuba, Japan) were grown in minimum essential medium (MEM, Invitrogen) supplemented with 10\% CS (Invitrogen). 


\section{Reagents}

The relevant reagents were purchased from Sigma (LPS (from Escherichia coli Serotype 0111:B4) and prostaglandin $\left.A_{1}\left(P G A_{1}\right)\right), R$ \& D Systems (rTNF $\alpha$ and IL-1 $\beta$ ) and Calbiochem (MG132).

\section{Western blotting and immunoprecipitation}

The sources of antibodies are as follows: rat anti-caspase-11, caspase-1 and Bid antibodies; ${ }^{1,24}$ anti-tubulin, Flag and HA antibodies (Sigma); antiphospho-Stat1, Stat1, $I_{\kappa} \mathrm{B} \alpha$ and ubiquitin antibodies (Santa Cruz Biotech.); Phospho- $\mid \kappa \mathrm{Ba}$ (Ser32) rabbit polyclonal antibody (Cell Signaling Technology); HRP-anti rat, rabbit and mouse IgG $(H+L)$ 's (Southern Biotechnology). Immunoprecipitation followed ${ }^{3}$ with agarose conjugated$\mathrm{I} \kappa \mathrm{B} \alpha$ rabbit polyclonal antibody (Santa Cruz Biotech.). The amount of IL$1 \beta$ in culture supernatant was determined by ELISA.

\section{Isolation of wedelolactone from $E$. prostrata $L$.}

E. prostrata L. were purchased from a Chinese herb store in Boston. Dried entire plants of $E$. prostrata L. $(40 \mathrm{~g})$ were homogenized in ethanol with a blender. The ethanol extract was filtered through cotton cloth and centrifuged at $10000 \mathrm{~g}$ for $30 \mathrm{~min}$. The supernatant was concentrated by evaporation and then washed with hot water. The hot water fraction was partitioned with ethyl acetate and the ethylacetate fraction was concentrated by evaporation. The dried ethylacetate fraction was dissolved in ethanol $(15 \mathrm{ml})$ and the supernatant was used as the ethylacetate fraction. The ethylacetate fraction was further fractionated by Toyopearl HW40 column chromatography and reverse-phase HPLC using a C18 column. The precipitate appeared in the ethylacetate fraction in ethanol with elapse of time, was washed several times, dissolved in a small amount of DMSO and recrystallized in ethanol. Both the precipitate and the active component separated by HPLC were identified as wedelolactone by UV spectrum, MS spectra and ${ }^{13} \mathrm{C}$ - and ${ }^{1} \mathrm{H}-\mathrm{NMR}$. The purity estimated by HPLC was $98-100 \%$. The analytical data of the purified active component were in agreement with the data of synthesized wedelolactone. A total of $7 \mathrm{mg}$ of wedelolactone was obtained from $50 \mathrm{~g}$ of dry plants.

\section{Synthesis of wedeloalctone and the derivatives}

Demethylwedelolactone and 11,12-dihydroxy coumestan were synthesized by the method of Pandy et al. ${ }^{25}$ Method for synthesis of wedelolactone and other derivatives will be described somewhere else (Z Yang et al., manuscript in preparation).

\section{RT-PCR}

The primers used for PCR to amplify caspase- 11 were M34 (CATGGCTGAAAACAAACACCC) and NOV1 (GCTGTAAGCTCCTCTTTCAC).

\section{Measurement of NF- $\kappa \mathrm{B}$ transcriptional activity}

The luciferase activity was measured by a luminometer using Steady-Glo luciferase assay system (Promega).

\section{Measurement of NF- $\kappa$ B DNA binding activity}

DNA binding activity of NF- $\kappa$ B p 65 was determined by a TransAM NF- $\kappa$ B p65 Chemi kit. The NF- $\kappa$ B p65 bound to the immobilized oligonucleotide containing a p65 binding site was detected by ELISA with chemiluminescent reagent.

\section{Kinase assay}

IKK kinase assay was as described by Kwak et al. ${ }^{26}$ with agaroseconjugated anti-IKK $\alpha$ rabbit polyclonal antibody (Santa Cruz Biotech.), anti-Flag mouse monoclonal antibody (Sigma) or anti-HA mouse monoclonal antibody (Santa Cruz Biotech). The thiophosphorylated- $I_{\kappa} \mathrm{B} \alpha$ $(1-317)$ created in the kinase assay was analyzed by SDS-PAGE and Western blotting using the antibody PhosphoFIND ${ }^{\mathrm{TM}}$ (Boston Biologicals).

\section{Acknowledgements}

We thank Dr. Alfred Goldberg for advice in measuring protein degradation. This work was supported in part by grants from NIA (to JY), a grant from the Chinese National Academy of Sciences (to CY and JY) and a grant-inaid from the Science and Technology Agency and the Ministry of Agriculture, Forestry and Fisheries of the Japanese Government (to MK). We thank Dr. T Okunishi for help with the purification of wedelolactone, Dr. Lin Li for NF- $\kappa$ B-luciferase construct and helpful comments, and Dr. M Yoshida and Dr. M Ohnishi-Kameyama for the NMR and Mass spectrum analysis of purified wedelolactone.

\section{References}

1. Wang S, Miura M, Jung YK, Zhu H, Gagliardini V, Shi L, Greenberg AH and Yuan J (1996) Identification and characterization of Ich-3, a member of the interleukin-1 $\beta$ converting enzyme (ICE)/Ced-3 family and an upstream regulator of ICE. J. Biol. Chem. 271: 20580-20587

2. Wang S, Miura M, Jung YK, Zhu H, Li E and Yuan J (1998) Murine caspase-11, an ICE-interacting protease, is essential for the activation of ICE. Cell 92: 501509

3. Kang SJ, Wang S, Hara H, Peterson EP, Namura S, Amin-Hanjani S, Huang Z, Srinivasan A, Tomaselli KJ, Thornberry NA, Moskowitz MA and Yuan J (2000) Dual role of caspase-11 in mediating activation of caspase-1 and caspase-3 under pathological conditions. J. Cell Biol. 149: 613-622

4. Li P, Allen H, Banerjee S, Franklin S, Herzog L, Johnston C, McDowell J, Paskind M, Rodman L, Salfeld J, Towne E, Tracey D, Wardwell S, Wei FY, Wong W, Kamen R and Seshadri T (1995) Mice deficient in IL-1 $\beta$-converting enzyme are defective in production of mature $\mathrm{IL}-1 \beta$ and resistant to endotoxic shock. Cell 80: 401-411

5. Ghayur T, Baneriee S, Hugunin M, Butler D, Herzog L, Carter A, Quintal L, Sekut L, Talanian R, Paskind M, Wong W, Kamen R, Tracey D. and Allen H (1997) Caspase-1 processes IFN- $\gamma$-inducing factor and regulates LPS-induced IFN- $\gamma$ production. Nature 386: 619-623

6. Kang SJ, Wang S, Kuida K and Yuan J (2002) Distinct downstream pathways of caspase-11 in regulating apoptosis and cytokine maturation during septic shock response. Cell Death Differ. 9: 1115-1125

7. Hisahara S, Yuan J, Momoi T, Okano H and Miura M (2001) Caspase-11 mediates oligodendrocyte cell death and pathogenesis of autoimmunemediated demyelination. J. Exp. Med. 193: 111-122

8. Lin XY, Choi MSK and Porter AG (2000) Expression analysis of the human caspase- 1 subfamily reveals specific regulation of the CASP5 gene by lipopolysaccharide and interferon- $\gamma$. J. Biol. Chem. 275: 39920-39926

9. Wangner H, Geyer B, Kiso Y, Hikino H and Rao GS (1986) Coumestans as the main active principles of the liver drugs Eclipta alba and Wedelia calendulacea. Planta Med. 52: 370-374

10. Melo PA, Nascimento MC, Mors WB and Suarez-Kurtz G (1994) Inhibition of the mytotoxic and hemorrhagic activities of crotalid venoms by Eclipta prostrata (Asteraceae) extracts and constituents. Toxicon 32: 595-603

11. Baeuerle PA (1998) $\left.\right|_{\kappa} \mathrm{B}-\mathrm{NF}-\kappa \mathrm{B}$ structures: at the interface of inflammation control. Cell 95: 729-731 
12. Li X, Massa PE, Hanidu A, Peet GW, Aro P, Savitt A, Mishe S, Li J and Marcu $\mathrm{KB}$ (2002) IKK $\alpha$, IKK $\beta$, and NEMO/IKK $\gamma$ are each required for the NF- $\kappa \mathrm{B}$ mediated inflammatory response program. J. Biol. Chem. 277: 45129-45140

13. Schauvliege R, Vanrobaeys J, Schotte P and Beyaert R (2002) Caspase-11 gene expression in response to lipopolysaccharide and interferon- $\gamma$ requires nuclear factor $-\kappa \mathrm{B}$ and signal transducer and activator of transcription (STAT) 1. J. Biol. Chem. 277: 41624-41630

14. Johnson C, Van Antwerp D and Hope TJ (1999) An N-terminal nuclear export signal is required for the nucleocytoplasmic shuttling of $I_{\kappa} \mathrm{B} \alpha$. EMBO J. 18: 6682-6693

15. Fisher C, Page S, Weber M, Eisele T, Neumeier D and Brand K (1999) Differential effects of lipopolysaccharide and tumor necrosis factor on monocytic $I_{\kappa} \mathrm{B}$ kinase signalsome activation and $\mathrm{I}_{\kappa} \mathrm{B}$ proteolysis. J. Biol. Chem. 274: 24625-24632

16. Chen ZJ, Parent L and Maniatis T (1996) Site-specific phosphorylation of $I_{\kappa} \mathrm{B} \alpha$ by a novel ubiquitination-dependent protein kinase activity. Cell 84 853-862

17. Rossi A, Kapahi P, Natoli G, Takahashi T, Chen $Y$, Karin M and Santoro MG (2000) Anti-inflammatory cyclopentenone prostaglandins are direct inhibitors of $1 \kappa B$ kinase. Nature 403: 103-118

18. Scherer DC, Brockman JA, Chen Z, Maniatis T and Ballard DW (1995) Signalinduced degradation of $\mathrm{I}_{\kappa} \mathrm{B} \alpha$ requires site-specific ubiquitination. Proc. Natl. Acad. Sci. USA 92: 11259-11263
19. Mercurio F, Zhu H, Murray BW, Shevchenko A, Bennett BL, Li JW, Young DB, Barbosa M, Mann M, Manning A and Rao A (1997) IKK-1 and IKK-2: cytokineactivated $I \kappa B$ kinase essential for NF- $\kappa B$ activation. Science $278: 860-866$

20. O'Connel MA, Bennet BL, Mercurio F, Manning AM and Mackman N (1998) Role of IKK1 and IKK2 in lipopolysaccharide signaling in human monocytic cells. J. Biol. Chem. 273: 30410-30414

21. Delhase M, Hayakawa M, Chen Y and Karin M (1999) Positive and negative regulation of $I_{\kappa} B$ kinase activity through $\operatorname{IKK} \beta$ subunit phosphorylation. Science 284: 309-313

22. Kwok BH, Koh B, Ndubusi MI, Elofsson M and Crews CM (2001) The antiinflammatory natural product parthenolide from the medicinal herb feverfew directly binds to and inhibits $\mid \kappa B$ kinase. Chem. Biol. 8: 759-766

23. Bowie AG and O'Nell LAJ (2000) Vitamin C inhibits NF- $\kappa$ B activation by TNF via the activation of p38 mitogen-activated protein kianse. J. Immunol. 165: 7180-7188

24. Li H, Zhu H, Xu CJ and Yuan J (1998) Cleavage of BID by caspase 8 mediates the mitochondrial damage in the Fas pathway of apoptosis. Cell 94: 491-501

25. Pandey G, Muralikrishna C and Bhalerao UT (1989) Mushroom tyrosinase catalysed synthesis of coumestans, benzofuran derivatives and related heterocyclic compounds. Tetrahedron 45: 6867-6874

26. Kwak YT, Guo J, Shen J and Gaynor RB (2000) Analysis of domains in the IKK $\alpha$ and IKK $\beta$ proteins that regulate their kinase activity. J. Biol. Chem. 275: 14752-14759 